\title{
Structural effect of phenyl ring compared to thiadiazole based adamantyl-sulfonamides on carbonic anhydrase inhibition th
}

\author{
Shyamasri Biswas a ${ }^{\text {, Fabrizio Carta }}{ }^{\mathrm{b}}$, Andrea Scozzafava ${ }^{\mathrm{b}}$, Robert McKenna ${ }^{\mathrm{a}, *}$, Claudiu T. Supuran ${ }^{\mathrm{b}, \mathrm{c}, *}$ \\ ${ }^{a}$ Department of Biochemistry and Molecular Biology, College of Medicine, University of Florida, PB 100245, Gainesville, FL 32610, USA \\ ${ }^{\mathrm{b}}$ Università degli Studi di Firenze, Polo Scientifico, Laboratorio di Chimica Bioinorganica, Rm. 188, Via della Lastruccia 3, 50019 Sesto Fiorentino, Florence, Italy \\ ' Università degli Studi di Firenze, NEUROFARBA Department, Section of Pharmaceutical Chemistry, Via Ugo Schiff 6, 50019 Sesto Fiorentino, Florence, Italy
}

\section{A R T I C L E I N F O}

\section{Article history:}

Received 3 January 2013

Accepted 6 February 2013

Available online 21 February 2013

\section{Keywords:}

Carbonic anhydrase

Benzenesulfonamide

Adamantyl

X-ray crystallography

Isoform-selective inhibitor

\begin{abstract}
A B S T R A C T
We investigated the inhibitory activity of sulfonamides incorporating adamantyl moieties against the physiologically relevant human (h) CA (EC 4.2.1.1) isoforms hCA I, II III (cytosolic), IX and XII (transmembrane, tumor-associated). The presence of a benzenesulfonamide instead of an 1,3,4-thiadiazole-sulfonamide fragment in the molecule of CA inhibitors (CAIs) drastically affects both inhibition efficacy and binding within the enzyme active site, as rationalized by means of X-ray crystallography of the adduct of hCA II with 4-(1-adamantylcarboxamidomethyl)benzenesulfonamide. Comparing the present X-ray structure with that of the corresponding 1,3,4-thiadiazole-sulfonamide compound possessing the 1-adamantylcarboxamide moiety, important differences of binding emerged, which explain the highly different inhibition profile of the two compounds against the investigated CA isoforms, most of which (CA I, II, IX and XII) are important drug targets.
\end{abstract}

() 2013 Elsevier Ltd. All rights reserved.

\section{Introduction}

In previous work from our laboratories ${ }^{1,2}$ we investigated the drug design of carbonic anhydrase (CA, EC 4.2.1.1) inhibitors (CAIs) incorporating the sulfonamide zinc-binding group (ZBG) and the adamantyl moieties. The interest in such derivatives was due to the fact that the adamantyl group induces an increased hydrophobicity to the compounds containing it, a property useful for targeting CA isoforms present in the brain, ${ }^{3}$ and which are inaccessible by the more hydrophilic sulfonamides such as the clinically used agent acetazolamide (5-acetamido-1,3,4-thiadiazole-2-sulfonamide) AZA. ${ }^{4-6}$ Furthemore, considering the wealth of structural data available for CA-sulfonamide adducts, ${ }^{7,8}$ it appeared of interest to investigate how this bulky moiety accommodates within the enzyme active site, and how this influences biological activity. ${ }^{2}$ Indeed, many sulfonamide CAIs incorporating both heterocyclic (e.g., 1,3,4-thiadiazole-2-sulfonamide) and aromatic (mostly benzenesulfonamide) moieties, to which adamantyl-1-carboxamido- or adamantyl-1-methylcarboxamido-groups have been attached, were reported, of which compounds 1-4 are the most investigated derivatives. ${ }^{1}$ Their interaction with the physiologically dominant

\footnotetext{
Coordinates and structure factors have been deposited in the Protein Data Bank as entry 4ILX.

* Corresponding authors. Tel.: +1 352392 5696; fax: +1 3523923422 (R.M.); tel.: +39055 4573005; fax: +39055 4573385 (C.T.S.).

E-mail addresses: rmckenna@ufl.edu (R. McKenna), claudiu.supuran@unifi.it (C.T. Supuran).
}

human (h) cytosolic CA isoforms hCA I and II has been studied by means of kinetic methods, and one such compound, the adamantylcarboxamido analog of acetazolamide, compound $\mathbf{1}$, has also been crystallized in adduct with hCA II, allowing us to understand the interaction between the scaffold of this inhibitor and the active site of the enzyme at molecular level. ${ }^{2}$

Sulfonamides and their isosteres (sulfamates, sulfamides, ureates and hydroxamates) are pharmacologically relevant CAIs, with applications as antiglaucoma, antiobesity, antiepileptic, antitumor and diuretic drugs. ${ }^{3-8}$ Although X-ray crystal structures are available for the majority of the twelve catalytically active members of the CA family (i.e., isozymes I-VA, IX, XII, XIII and XIV), ${ }^{9,10}$ most of the reported complexes with inhibitors regard isozyme hCA II (and to a less extent hCA I). These data are relevant for the drug design of isozyme-selective CAIs, and important such advances have been made in the last years, mainly by rationalizing the various sub-pockets for the binding of sulfonamide/sulfamide/sulfamate inhibitors done by McKenna's and our groups. ${ }^{6-9}$ In fact, the main problem with the classical, clinically used sulfonamides is related to the fact that they are promiscuous inhibitors of all (or most of the) CA isozymes found in mammals. ${ }^{3}$ Thus, understanding at molecular level the detailed interaction between the scaffold of the inhibitor and the amino acid residues involved in its binding, in each CA isoform, is crucial for obtaining isoform-selective CAIs. Here we extend our previous investigation on adamantyl-containing sulfonamides, and report a crystallographic study of one such compound (incorporating the benzenesulfonamide moiety) in complex with hCA II. We also compare its binding with the adama- 
tylcarboxamido-1,3,4-thiadiazole-2-sulfonamide reported earlier. ${ }^{2}$ Molecular modeling has also been employed to investigate the interaction of these inhibitors with isoforms more difficult to crystallize, such as hCA I, III, IX and XII, some of which are important drug targets. ${ }^{3,11,12}$ We were able to rationalize important differences in binding of the benzenesulfonamide versus the thiadiazole-sulfonamide derivatives incorporating such adamantyl moieties.

\section{Results and discussion}

\subsection{Chemistry}

The adamantyl-containing aromatic/heterocyclic sulfoamides 1-4 have been reported earlier, ${ }^{1}$ being prepared by reaction of the corresponding amino-sulfonamides with adamantyl-1-carboxyl chloride or adamantyl-1-methylcarboxyl chloride.

\subsection{X-ray crystallography and docking studies}

The structure of hCA II complexed with $\mathbf{4}$ has been determined to $1.6 \AA$ resolution (Table 1 ). Compound $\mathbf{4}$ is well ordered and refined with full occupancy, with $B$ factors that were comparable to the solvent within the active site (Fig. 1A and Table 1). Similar to other sulfonamide inhibitors bound to hCA II, the sulfonamide amine nitrogen of $\mathbf{4}$ binds directly to the active site zinc ion along with the side chains of His94, His96 and His119. ${ }^{6-9}$ The overall $\mathrm{Zn}(\mathrm{N})_{4}$ coordination can be described as a distorted tetrahedron. All other interactions between the sulfamoyl ZBG moiety and the conserved residues Thr199/Glu106 are also preserved in this structure, as in the ones of CAs with other sulfonamide/sulfamate/sulfamide inhibitors (data not shown) investigated so far. ${ }^{6-9}$

Compared with the X-ray structure of the hCA II-1 derivative, ${ }^{2}$ sulfonamide 4 contains an extra $\mathrm{CH}_{2}$ group between the benzenesulfonamide and the adamantyl fragments of the molecule, which confers a greater degree of flexibility to the tail and permits significant differences in the orientation of the bulky adamantyl moiety when in complex with the enzyme. Thus, one of the salient features of this complex was that whereas the adamantyl group in the structure of hCA II-1 complex (PDB accession 3MHC) $)^{2}$ was located between Phe131 and Ile91, the derivative $\mathbf{4}$ investigated here has the adamantyl group located between Phe131 and Val135 (Fig. 1A and B). In this way, inhibitor 4 favors binding of its adamantyl tail to the common, hydrophobic pocket 1 of hCA II, which is located towards Phe131 rather than pocket 2, reported earlier by our groups and located between Phe131 and Ile91. ${ }^{13}$ Compound 4 forms a hydrogen bond with residue Gln92, but this bond is weaker compared to the ones of the earlier reported adamantyl analog of acetazolamide 1, which makes a hydrogen bond with this residue, but also participates in a network of other hydrogen bonds involving residues Thr200, Pro201 and an ordered water molecule. ${ }^{2}$ The buried surface area of $\mathbf{4}$, calculated by the program PISA $^{14}$ is of $\sim 520 \AA^{2}$ which is a relatively high value, due to the fact that the adamantyl ring is placed in-between the hydrophobic pocket (nearby Phe131) and Pro202 (Fig. 1A).

The present structure was superimposed to that of other CA isoforms in order to better understand the contribution of the adamantyl tail to the isoform selectivity profile of these inhibitors. Residue Gln92, involved in the binding of $\mathbf{4}$, is conserved in hCA $\mathrm{II}^{2}{ }^{2}$ hCA I, ${ }^{15}$ hCA III, ${ }^{16}$ hCA IX ${ }^{12}$ and hCA XII, ${ }^{17}$ hence the hydrogen bond between the oxygen atom of compound 4 and Gln92 will likely remain same in all of these isoforms (Fig. 2). The presence of this bulky side chain in the middle of the active site of hCA III will prevent any similar sulfonamide derivative from binding effectively to hCA III. Residue Phe 131 of hCA II is replaced by the smaller side chain Val131 in hCA IX and Ala131 in hCA XII, which probably will allow the drug to sit into this pocket with a greater degree of freedom. However Phe131 makes this pocket more hydrophobic, hence this drug will be a better inhibitor for hCA II than the cancer specific isoforms hCA IX and hCA XII. Another residue close to the drug tail in the present structure is Val135, which is replaced by less hydrophobic tails such as Ser135 in hCA XII and Ala 135 in hCA I, hence this drug will most likely be a weaker inhibitor for hCA XII and hCA I. In addition, Pro200 in hCA II, hCA IX and hCA III is replaced by a bulky His200 in hCA I and a slightly shorter Thr200 in hCA XII. The bulky His200 residue in proximity to the inhibitor will make this drug a weaker inhibitor for hCA I compared to the thiadiazole derivative $\mathbf{1}$ investigated earlier. ${ }^{2}$ Based on the superposition of Figure 2, we predict that it is more likely that hCA IX will be better inhibited by a shorter chain adamantyl analog (as in compound $\mathbf{1}$ ) than the present drug 4, mainly due to the fact that 1 binds to the selective pocket 2 instead of the common

Table 1

Data and final model statistics for the hCA II-4 adduct

\begin{tabular}{|c|c|}
\hline PDB code & 4ILX \\
\hline Wavelength $(\AA)$ & 1.54 \\
\hline Space group & $P 2_{1}$ \\
\hline Unit cell parameters $\left(\AA,^{\circ}\right)$ & $a=42.4 b=41.3 c=72.1, \beta=104.0$ \\
\hline Measured reflections & 111,453 \\
\hline Unique reflections & 29,558 \\
\hline Resolution $(\AA)$ & $1.6(1.7-1.6)^{\mathrm{d}}$ \\
\hline$R_{\text {sym }}{ }^{\mathrm{a}}(\%)$ & 4.2 \\
\hline$I / \sigma I$ & $25.9(26.3)$ \\
\hline Completeness (\%) & $91.7(87.1)$ \\
\hline Redundancy & 3.8 \\
\hline$R_{\text {cryst }}{ }^{\mathrm{b}}(\%)$ & 14.66 \\
\hline$R_{\text {free }}{ }^{\mathrm{c}}(\%)$ & 17.7 \\
\hline No. residues & 257 \\
\hline No. protein atoms (including alternate conformation) & 2117 \\
\hline No. ligand atoms & 23 \\
\hline No. water molecules & 301 \\
\hline RMSD:bond lengths $(\AA ̊)$, angles $\left({ }^{\circ}\right)$ & $0.006,1.14$ \\
\hline Ramachandran statistics (\%): most favoured, additionally allowed and generously allowed regions & $0.0,2.6,97.4$ \\
\hline Average B factors $\left(\AA^{2}\right)$ : all, main-, side-chains, ligands, solvent & $16.0,12.2,15.8,21.2,29.0$ \\
\hline
\end{tabular}

${ }^{\mathrm{a}} R_{\mathrm{sym}}=\Sigma \mid I-\langle I>| / \Sigma<I>$.

b $R_{\text {work }}=\left(\Sigma\left|F_{\mathrm{o}}\right|-\left|F_{\mathrm{c}}\right| / \Sigma\left|F_{\text {obs }}\right|\right) \times 100$.

c $R_{\text {free }}$ is calculated in the same manner as $R_{\text {work }}$, except that it uses $5 \%$ of the reflection data omitted from refinement.

d Values in the parenthesis represents highest resolution bin. 

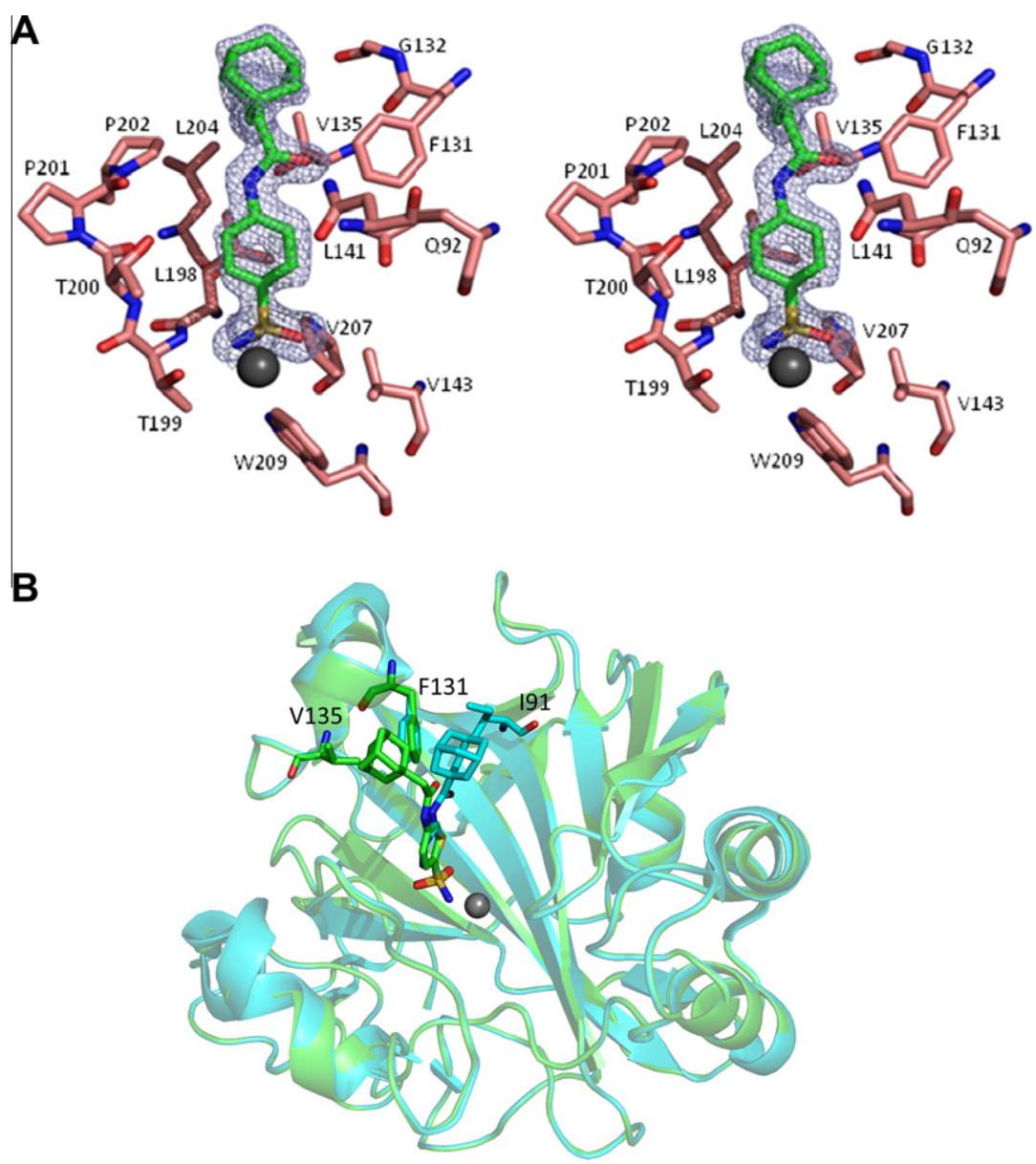

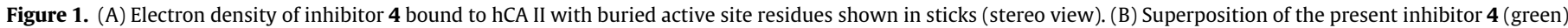
over previously reported adamantyl analog $\mathbf{1}$ (cyan). ${ }^{2}$ Active site residues in close proximity to the tail end of the inhibitor are indicated.

pocket 1 , in which derivative $\mathbf{4}$ was found. Collectively it can be predicted, based on the structure reported here (and the previous one), ${ }^{2}$ that the adamantyl group which is highly hydrophobic in nature, favor the binding of the inhibitors close to residues that are also hydrophobic in nature, such as Phe131, Val135 and Ile91 (Figs. 1 and 2). However, the discrimination whether the inhibitor will bind to the pocket 1 or 2 , is dictated by the nature of the organic scaffold to which the sulfamoyl ZBG is attached, and by the presence or absence of a linker between this scaffold and the adamantyl moiety.

\subsection{CA inhibition}

In order to check whether our predictions, based on the X-ray crystallography/docking studies presented above are true, we have investigated inhibition of CA isoforms I, II, III, IX and XII with compounds 1-4 (Table 2 ). It should be mentioned that originally, ${ }^{1}$ compounds incorporating adamantyl moieties were investigated only as hCA I and II inhibitors. In the previous crystallographic work, ${ }^{2}$ we have also investigated the inhibition of hCA IX and XII (antitumor drug targets $)^{6}$ with two such derivatives, the thiadiazole sulfonamides $\mathbf{1}$ and $\mathbf{2}$. Here we report the inhibition data of compounds 1-4 with five CA isoforms, hCA I, II, III (cytosolic isoforms), IX and XII (transmembrane enzymes) (Table 2). ${ }^{18}$

As seen from data of Table 2, all the prediction we made based on the crystallography/docking studies presented above, are in fact true: compounds $\mathbf{3}$ and $\mathbf{4}$ incorporating a benzenesulfonamide instead of a thiadiazole-sulfonamide scaffold present in $\mathbf{1}$ and $\mathbf{2}$, were less effective CAIs against all investigated isoforms (probably due to the interactions mentioned in the crystallography/docking part of this study). However, several interesting facts emerged by looking into detail at these data. Thus, whether for the cytosolic isoforms hCA I, II, and III the benzenesulfonamides $\mathbf{3}$ and $\mathbf{4}$ were several orders (1-2) of magnitude weaker CAIs compared to the thiadiazole-sulfonamides $\mathbf{1}$ and $\mathbf{2}$, in the case of the transmembrane isoforms hCA IX and XII, there were only minor differences of potency between the two types of derivatives. Thus, against hCA IX 1 and 2 were effective inhibitors ( $K_{\mathrm{I}} \mathrm{S}$ of $\left.6.4-49.5 \mathrm{nM}\right)$ but almost the same type of inhibition profile was observed for $\mathbf{3}$ and $4\left(K_{\mathrm{I}} \mathrm{s}\right.$ of $\left.51.3-56.5 \mathrm{nM}\right)$. The same situation (with even less differences of potency) was observed for the inhibition of hCA XII: derivatives 1 and 2 were low nanomolar inhibitors ( $K_{\mathrm{I}} \mathrm{S}$ of $\left.2.8-4.7 \mathrm{nM}\right)$ but 3 and 4 also showed inhibition constants in the same range, of 7.1-9.4 nM (Table 2). This inhibition profile outlined above render the benzenesulfonamides incorporating adamantyl moieties (such as $\mathbf{3}$ and 4) isoform-selective inhibitors for the tumor-associated isoforms versus the cytosolic ones hCA I and II, a profile not shared with the structurally-related 1,3,4-thiadiazole-sulfonamides (such as $\mathbf{1}$ and $\mathbf{2}$ ).

\section{Conclusions}

We investigated the inhibitory activity of sulfonamides incorporating adamantyl moieties against several physiologically relevant isoforms, that is, hCA I, II III (cytosolic), IX and XII (transmembrane, tumor-associated). The presence of a benzenesulfonamide instead of an 1,3,4-thiadiazole-sulfonamide fragment in the molecule of such inhibitors drastically affects both inhibition 


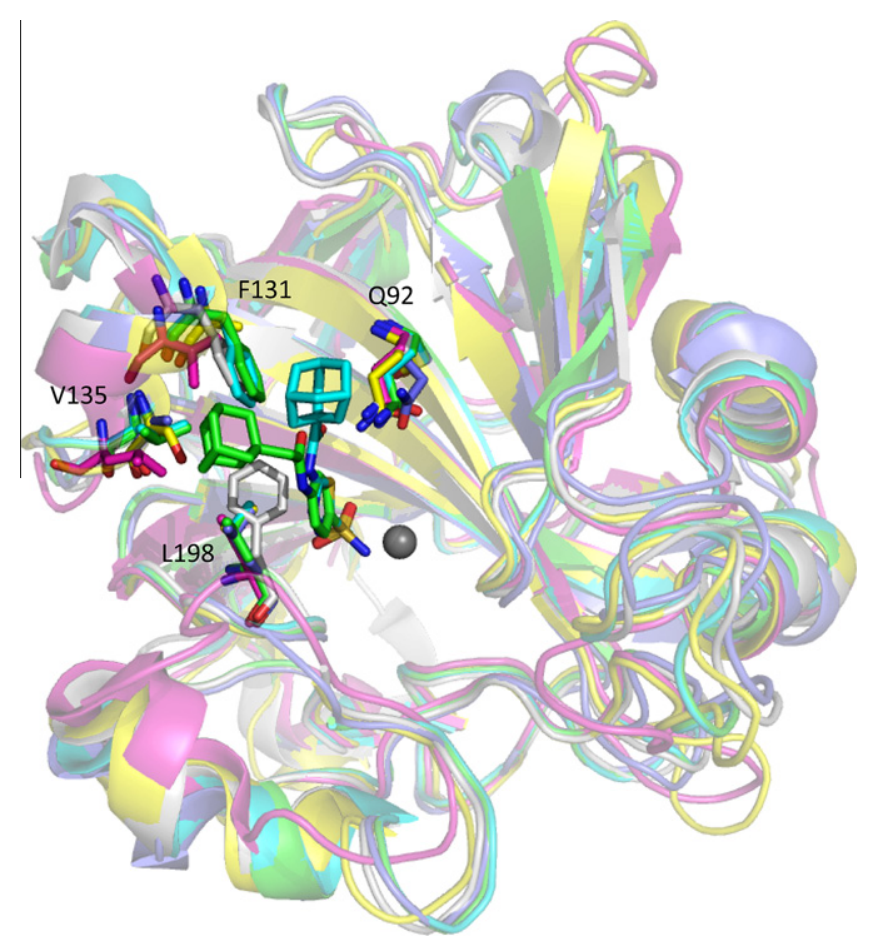

Figure 2. Overlay of hCAII with compound $\mathbf{4}$ (green), hCA II with earlier reported adamantyl analog 1 (cyan), hCA IX (pink), hCA XII (yellow), hCA III (grey) and hCA I (purple). Residues Q92, F131, V135 and L198 of hCAII are shown in sticks.

efficacy and binding within the enzyme active site, as rationalized by means of X-ray crystallography/docking studies of the adduct of 4-(1-adamantylcarboxamidomethyl)benzenesulfonamide with these isoforms. Comparing the X-ray structure of this compound bound to hCA II with that of the corresponding 1,3,4-thiadiazolesulfonamide compound possessing the 1-adamantylcarboxamide moiety, important differences of binding emerged, which explain the highly different inhibition profile of the two compounds against the investigated CA isoforms, most of which (CA I, II, IX and XII) are important drug targets. Indeed, the aromatic derivative binds in the commonly utilized hydrophobic pocket within the hCA II active site (between Phe131 and Val135), whereas the thiadiazole derivatives binds in the less utilized pocket (defined by
Phe131 and Ile91). This binding mode and the differences of amino acid residues within these isoforms active sites, render the benzenesulfonamide derivatives incorporating adamantyl groups CA IX/XII-selective inhibitors.

\section{Materials and methods}

\subsection{Chemistry}

Compounds 1-4 were reported earlier by one of our groups. ${ }^{1}$

\subsection{X-ray crystallography and structure determination}

hCA II was purified to electrophoretic homogeneity according to previously described protocol. ${ }^{2}$ For crystallization, the sulfonamide 4 was directly added to the well solution. The drug was initially dissolved in $100 \%$ DMSO, and dilution with the crystallization bufffer was done till a final DMSO concentration $0.2 \%$ has been reached in the drop. The crystallization drops were setup according to the hanging drop vapor diffusion method by mixing $5 \mu$ l of precipitant with $5 \mu$ l of protein. ${ }^{2}$ A protein to drug ratio of $1: 2$ was used for this study. The protein concentration used in the drop was of $450 \mu \mathrm{M}$. The crystallization conditions were: $1.6 \mathrm{M}$ sodium citrate, $50 \mathrm{mM}$ Tris, $\mathrm{pH}$ 8.0. Crystals appeared within $48 \mathrm{~h}$ of incubation at room temperature. In addition to co-crystallization, crystals were also soaked in drug and immersed in precipitant solution containing $25 \%$ glycerol just before mounting it directly into liquid nitrogen stream for data collection. Dataset was collected using a Rigaku RU H3R Cu rotating anode at $50 \mathrm{kV}$ and $20 \mathrm{~mA}$. The temperature for data collection was $100 \mathrm{~K}$ and an R-AXIS IV ${ }^{++}$image plate system with Osmic Varimax Optics was used for recording images. The crystal to detector distance was $80 \mathrm{~mm}$ with $1^{\circ}$ oscillation and 5 min exposure per frame. Crystals diffracted to a resolution of $1.6 \AA$ (Table 1). The images were processed using HKL2000. ${ }^{19}$

The structure was solved by molecular replacement using a high resolution structure (2ILI) of hCA II as a starting model. ${ }^{20}$ The program PHASER in PHENIX ${ }^{21}$ was used to get the initial phases. The ligand coordinates were generated using PRODRG ${ }^{22}$ and the restraints files using PHENIX eLBOW. ${ }^{21}$ Refinement was carried out in PHENIX by setting aside 5\% of reflections for $R_{\text {free }}$ calculations. Iterative model building was performed in $\mathrm{COOT}^{23}$ until a reasonable $R_{\text {cryst }}$ was achieved. The validity of the model was checked using MOLPROBITY. ${ }^{24}$ All figures are made using PYMOL. ${ }^{25}$

Table 2

Inhibition of human $\alpha$-CA (hCA) isozymes I, II, III, IX and XII with sulfonamides 1-4 and AZA (as standard), by a stopped-flow $\mathrm{CO}_{2}$ hydrase assay ${ }^{18}$<smiles>CC(=O)Nc1nnc(S(N)(=O)=O)s1</smiles>

AZA<smiles>NS(=O)(=O)c1nnc(NC(=O)[Ga]2C3CC4CC(C3)CC2C4)s1</smiles>

1: $\mathrm{n}=0$

2: $n=1$<smiles>NS(=O)(=O)c1ccc(NC(=O)C2C3CC4CC(C3)CC2C4)cc1</smiles>

3: $n=0$

4: $n=1$

\begin{tabular}{|c|c|c|c|c|c|}
\hline \multirow[t]{2}{*}{ Inhibitor } & \multicolumn{5}{|c|}{$K_{\mathrm{I}}^{\mathrm{a}}(\mathrm{nM})$} \\
\hline & $\mathrm{hCA} \mathrm{I}^{\mathrm{b}}$ & hCA II ${ }^{\mathrm{b}}$ & hCA III ${ }^{\mathrm{d}}$ & hCA IX & hCA XII \\
\hline 1 & $850^{\mathrm{b}}$ & $10.0^{\mathrm{b}}$ & $1.2 \times 10^{6}$ & $6.4^{\mathrm{c}}$ & $2.8^{\mathrm{c}}$ \\
\hline 2 & $340^{\mathrm{b}}$ & $8.0^{\mathrm{b}}$ & $1.4 \times 10^{6}$ & $49.5^{c}$ & $4.7^{c}$ \\
\hline 3 & $18,600^{c}$ & $265^{c}$ & $>1.0 \times 10^{7}$ & $51.3^{\mathrm{d}}$ & $7.1^{\mathrm{d}}$ \\
\hline 4 & $15,100^{c}$ & $233^{c}$ & $>1.0 \times 10^{7}$ & $56.5^{d}$ & $9.4^{\mathrm{d}}$ \\
\hline AZA & $250^{\mathrm{b}}$ & $12^{\mathrm{b}}$ & $2 \times 10^{5} \mathrm{~b}$ & $25^{\mathrm{b}}$ & $2.5^{\mathrm{b}}$ \\
\hline
\end{tabular}

${ }^{\text {a }}$ Errors in the range of $\pm 10 \%$ of the reported data from three different assays by a stopped-flow $\mathrm{CO}_{2}$ hydration method. ${ }^{19}$

b From Ref. 1.

c From Ref. 2.

d This work. 
The data reduction statistics and refinement parameters are listed in Table 1.

Superposition of this compound (4) over that of derivative 1 (PDB code $3 \mathrm{MHC})^{2}$ bound gave a RMSD value of $0.116 \AA$, showing strong similarity between these structures.

\section{3. $C A$ inhibition}

An Applied Photophysics stopped-flow instrument has been used for assaying the CA catalysed $\mathrm{CO}_{2}$ hydration activity. Phenol red (at a concentration of $0.2 \mathrm{mM}$ ) has been used as indicator, working at the absorbance maximum of $557 \mathrm{~nm}$, with $20 \mathrm{mM}$ Hepes (pH 7.5 for the $\alpha$-CAs) as buffer, and $20 \mathrm{mM} \mathrm{Na}_{2} \mathrm{SO}_{4}$ (for maintaining constant the ionic strength), following the initial rates of the CA-catalyzed $\mathrm{CO}_{2}$ hydration reaction for a period of 10 100 s. $^{18}$ The $\mathrm{CO}_{2}$ concentrations ranged from 1.7 to $17 \mathrm{mM}$ for the determination of the kinetic parameters and inhibition constants. For each inhibitor at least six traces of the initial $5-10 \%$ of the reaction have been used for determining the initial velocity. The uncatalyzed rates were determined in the same manner and subtracted from the total observed rates. Stock solutions of inhibitor $(10 \mathrm{mM})$ were prepared in distilled-deionized water and dilutions up to $0.01 \mu \mathrm{M}$ were done thereafter with distilled-deionized water. Inhibitor and enzyme solutions were preincubated together for $15 \mathrm{~min}$ at room temperature prior to assay, in order to allow for the formation of the E-I complex. The inhibition constants were obtained by non-linear least-squares methods using PRISM 3, as reported earlier, ${ }^{26}$ and represent the mean from at least three different determinations. Human CA isozymes were prepared in recombinant form as reported earlier by our groups. ${ }^{27,28,9}$

\section{Acknowledgments}

This research was financed in part by two 7th FP EU projects (METOXIA and DYNANO) to A.S. and C.T.S., in part by a NIH GM25154 grant, and by a Thomas Maren grant to R.M. R.M. would also like to thank the Center of Structural Biology for support of the $\mathrm{X}$-ray facility at UF.

\section{References and notes}

1. Ilies, M. A.; Masereel, B.; Rolin, S.; Scozzafava, A.; Câmpeanu, G.; Cîmpeanu, V.; Supuran, C. T. Bioorg. Med. Chem. 2004, 12, 2717.

2. Avvaru, B. S.; Wagner, J. M.; Maresca, A.; Scozzafava, A.; Robbins, A. H.; Supuran, C. T.; McKenna, R. Bioorg. Med. Chem. Lett. 2010, 20, 4376.

3. (a) Supuran, C. T. Nat. Rev. Drug Disc. 2008, 7, 168; (b) Supuran, C. T.; Scozzafava, A. Bioorg. Med. Chem. 2007, 15, 4336; (c) Silverman, D. N. Biochim. Biophys. Acta 2010, 1804, 243; (d) Domsic, J. F.; Avvaru, B. S.; Kim, C. U.; Gruner, S. M.; Agbandje-McKenna, M.; Silverman, D. N.; McKenna, R. J. Biol. Chem. 2008, 283, 30766 .

4. (a) Supuran, C. T.; Scozzafava, A.; Casini, A. Med. Res. Rev. 2003, 23, 146; (b) Scozzafava, A.; Mastrolorenzo, A.; Supuran, C. T. Expert Opin. Ther. Pat. 2004, 14, 667; (c) Winum, J. Y.; Montero, J. L.; Scozzafava, A.; Supuran, C. T. Mini-Rev. Med. Chem. 2006, 6, 921; (d) Maren, T. H. Physiol. Rev. 1967, 47, 595.

5. (a) Pastorekova, S.; Parkkila, S.; Pastorek, J.; Supuran, C. T. J. Enzyme Inhib. Med. Chem. 2004, 19, 199; (b) Supuran, C. T.; Scozzafava, A.; Casini, A. Development of Sulfonamide Carbonic Anhydrase Inhibitors. In Carbonic Anhydrase-its Inhibitors and Activators; Supuran, C. T., Scozzafava, A., Conway, J., Eds.; CRC Press: Boca Raton, 2004; pp 67-147; (c) Mincione, F.; Scozzafava, A.; Supuran, C. T. Antiglaucoma Carbonic Anhydrase Inhibitors as Ophthalomologic Drugs.
In Drug Design of Zinc-Enzyme Inhibitors: Functional, Structural, and Disease Applications; Supuran, C. T., Winum, J. Y., Eds.; Wiley: Hoboken (NJ), 2009; pp 139-154.

6. (a) Alterio, V.; Di Fiore, A.; D’Ambrosio, K.; Supuran, C. T.; De Simone, G. Chem. Rev. 2012, 112, 4421; (b) Neri, D.; Supuran, C. T. Nat. Rev. Drug Disc. 2011, 10 , 767.

7. (a) Aggarwal, M.; Boone, C.D.; Kondeti, B.; McKenna, R. J. Enzyme Inhib. Med. Chem. 2013, 28, 267; (b) Aggarwal, M.; Kondeti, B.; McKenna, R Bioorg. Med. Chem. in press, 21, (pii: S0968-0896(12)00641-4. doi: http://dx.doi.org/ 10.1016/j.bmc.2012.08.019).

8. Supuran, C. T. J. Enzyme Inhib. Med. Chem. 2012, 27, 759.

9. (a) De Simone, G.; Vitale, R. M.; Di Fiore, A.; Pedone, C.; Scozzafava, A.; Montero, J. L.; Winum, J. Y.; Supuran, C. T. J. Med. Chem. 2006, 49, 5544; (b) De Simone, G.; Di Fiore, A.; Menchise, V.; Pedone, C.; Antel, J.; Casini, A.; Scozzafava, A.; Wurl, M.; Supuran, C. T. Bioorg. Med. Chem. Lett. 2005, 15, 2315; (c) Winum, J. Y.; Temperini, C.; El Cheikh, K.; Innocenti, A.; Vullo, D.; Ciattini, S.; Montero, J. L.; Scozzafava, A.; Supuran, C. T. J. Med. Chem. 2006, 49, 7024.

10. (a) Alterio, V.; Vitale, R. M.; Monti, S. M.; Pedone, C.; Scozzafava, A.; Cecchi, A.; De Simone, G.; Supuran, C. T. J. Am. Chem. Soc. 2006, 128, 8329; (b) Casini, A. Antel, J.; Abbate, F.; Scozzafava, A.; David, S.; Waldeck, H.; Schafer, S.; Supuran, C. T. Bioorg. Med. Chem. Lett. 2003, 13, 841; (c) Weber, A.; Casini, A.; Heine, A.; Kuhn, D.; Supuran, C. T.; Scozzafava, A.; Klebe, G. J. Med. Chem. 2004, 47, 550; (d) Menchise, V.; De Simone, G.; Alterio, V.; Di Fiore, A.; Pedone, C.; Scozzafava, A.; Supuran, C. T. J. Med. Chem. 2005, 48, 5721.

11. (a) Supuran, C. T.; Di Fiore, A.; De Simone, G. Expert Opin. Emerg. Drugs. 2008, 13, 383; (b) De Simone, G.; Di Fiore, A.; Supuran, C. T. Curr. Pharm. Des. 2008, 14, 655.

12. (a) Svastova, E.; Hulíkova, A.; Rafajova, M.; Zatovicova, M.; Gibadulinova, A.; Casini, A.; Cecchi, A.; Scozzafava, A.; Supuran, C. T.; Pastorek, J.; Pastorekova, S. FEBS Lett. 2004, 577, 439; (b) Thiry, A.; Dogné, J. M.; Masereel, B.; Supuran, C. T. Trends Pharmacol. Sci. 2006, 27, 566; (c) Alterio, V.; Hilvo, M.; Di Fiore, A.; Supuran, C. T.; Pan, P.; Parkkila, S.; Scaloni, A.; Pastorek, J.; Pastorekova, S.; Pedone, C.; Scozzafava, A.; Monti, S. M.; De Simone, G. Proc. Natl. Acad. Sci. U.S.A. 2009, 106, 16233.

13. Pacchiano, F.; Aggarwal, M.; Avvaru, B. S.; Robbins, A. H.; Scozzafava, A.; McKenna, R.; Supuran, C. T. Chem. Commun. 2010, 46, 8371.

14. Krissinel, E.; Henrick, K. J. Mol. Biol. 2007, 372, 774.

15. Chakravarty, S.; Kannan, K. K. J. Mol. Biol. 1994, 243, 298.

16. Duda, D. M.; Tu, C.; Fisher, S. Z.; An, H.; Yoshioka, C.; Govindasamy, L.; Laipis, P. J.; Agbandje-McKenna, M.; Silverman, D. N.; McKenna, R. Biochemistry 2005, 44 10046.

17. Whittington, D. A.; Waheed, A.; Ulmasov, B.; Shah, G. N.; Grubb, J. H.; Sly, W. S.; Christianson, D. W. Proc. Natl. Acad. Sci. U.S.A. 2001, 98, 9545.

18. Khalifah, R. G. J. Biol. Chem. 1971, 246, 2561.

19. Otwinowski, Z.; Minor, W. Methods Enzymol. 1997, 276, 307.

20. Fisher, S. Z.; Maupin, C. M.; Budayova-Spano, M.; Govindasamy, L.; Tu, C. K.; Agbandje-McKenna, M.; Silverman, D. N.; Voth, G. A.; McKenna. R. Biochemistry 2007, 42, 2930.

21. Adams, P. D.; Afonine, P. V.; Bunkoczi, G.; Chen, V. B.; Davis, I. W.; Echols, N.; Headd, J. J.; Hung, L. W.; Kapral, G. J.; Grosse-Kunstleve, R. W.; McCoy, A. J.; Moriarty, N. W.; Oeffner, R.; Read, R. J.; Richardson, D. C.; Richardson, J. S.; Terwilliger, T. C.; Zwart, P. H. Acta Crystallogr. D 2010, D66, 213.

22. Schuttelkopf, A. W.; van Aalten, D. M. Acta Crystallogr. D 2004, D60, 1355

23. Emsley, P.; Cowtan, K. Acta Crystallogr. D 2004, D60, 2126.

24. Chen, V. B.; Arendall, W. B., 3rd; Headd, J. J.; Keedy, D. A.; Immormino, R. M.; Kapral, G. J.; Murray, L. W.; Richardson, J. S.; Richardson, D. C. Acta Crystallogr. D 2010, D66, 12.

25. The PyMOL Molecular Graphics System. Version 1.3.

26. (a) Vullo, D.; Franchi, M.; Gallori, E.; Pastorek, J.; Scozzafava, A.; Pastorekova, S.; Supuran, C. T. Bioorg. Med. Chem. Lett. 2003, 13, 1005; (b) Vullo, D.; Innocenti, A.; Nishimori, I.; Pastorek, J.; Scozzafava, A.; Pastorekova, S.; Supuran, C. T. Bioorg. Med. Chem. Lett. 2005, 15, 963; (c) Liu, F.; Martin-Mingot, A.; Lecornué, F.; Jouannetaud, M. P.; Maresca, A.; Thibaudeau, S.; Supuran, C. T. J. Enzyme Inhib. Med. Chem. 2012, 27, 886.

27. (a) Menchise, V.; De Simone, G.; Di Fiore, A.; Scozzafava, A.; Supuran, C. T. Bioorg. Med. Chem. Lett. 2006, 16, 6204; (b) Fabrizi, F.; Mincione, F.; Somma, T.; Scozzafava, G.; Galassi, F.; Masini, E.; Impagnatiello, F.; Supuran, C. T. J. Enzyme Inhib. Med. Chem. 2012, 27, 138.

28. (a) Vullo, D.; Voipio, J.; Innocenti, A.; Rivera, C.; Ranki, H.; Scozzafava, A.; Kaila K.; Supuran, C. T. Bioorg. Med. Chem. Lett. 2005, 15, 971; (b) Bootorabi, F.; Jänis, J.; Hytönen, V. P.; Valjakka, J.; Kuuslahti, M.; Vullo, D.; Niemelä, O.; Supuran, C. T.; Parkkila, S. J. Enzyme Inhib. Med. Chem. 2011, 26, 862. 